\title{
LETTERS
}

\section{Consider the economic burden for patients}

I read with interest the commentary by Mr. Matthew Herder and Dr. David Juurlink proposing ministerial recall of high-dose opioid formulations. ${ }^{1}$

Unquestionably, some "legacy patients" had their opioid doses gradually increased to large doses, but many of these patients have been stable and functional. In response to the new guidelines, ${ }^{2}$ many such patients are successfully undergoing slow reductions. The initial reductions will see the continued use of high-dose products until the total opioid burden begins to decrease.

My concern is the financial difficulty these patients will incur, given that double the number of tablets may be more expensive. Patients already feel stigmatized by media coverage as they attempt to reduce their dosage or convert to a less potent formulation.
As patients reduce or convert, and as new patients are not having the same dose escalations, the high-dose products will eventually fade away. The main concern I have with the authors' recommendations is the increased economic burden for patients currently taking opioids or their insurers.

\section{Stanley Lofsky MD}

Family physician; honorary member, North York General Hospital Medical Staff Association, Toronto, Ont.

Cite as: CMAJ 2019 March 18;191:E317. doi: $10.1503 / \mathrm{cmaj} .71577$

\section{References}

1. Herder M, Juurlink D. High-strength opioid formulations: the case for a ministerial recall. CMAJ 2018;190:E1404-5.

2. Busse JW, Craigie S, Juurlink DN, et al. Guideline for opioid therapy and chronic noncancer pain. CMAJ 2017;189:E659-66.

Competing interests: None declared. 